ARTICLE

\title{
Li-ion storage properties of two-dimensional titanium-carbide synthesized via fast one-pot method in air atmosphere
}

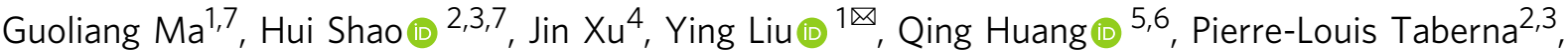
Patrice Simon (1) ${ }^{1,2,3 凶} \&$ Zifeng Lin (1) ${ }^{1 \times}$

Structural bidimensional transition-metal carbides and/or nitrides (MXenes) have drawn the attention of the material science research community thanks to their unique physicalchemical properties. However, a facile and cost-effective synthesis of MXenes has not yet been reported. Here, using elemental precursors, we report a method for MXene synthesis via titanium aluminium carbide formation and subsequent in situ etching in one molten salt pot. The molten salts act as the reaction medium and prevent the oxidation of the reactants during the high-temperature synthesis process, thus enabling the synthesis of MXenes in an air environment without using inert gas protection. $\mathrm{Cl}$-terminated $\mathrm{Ti}_{3} \mathrm{C}_{2} \mathrm{~T}_{x}$ and $\mathrm{Ti}_{2} \mathrm{CT}_{x}$ MXenes are prepared using this one-pot synthetic method, where the in situ etching step at $700{ }^{\circ} \mathrm{C}$ requires only approximately 10 mins. Furthermore, when used as an active material for nonaqueous Li-ion storage in a half-cell configuration, the obtained $\mathrm{Ti}_{2} \mathrm{CT}_{x} \mathrm{MXene}$ exhibits lithiation capacity values of approximately $280 \mathrm{mAh} \mathrm{g}^{-1}$ and $160 \mathrm{mAh} \mathrm{g}^{-1}$ at specific currents of $0.1 \mathrm{Ag}^{-1}$ and $2 \mathrm{Ag}^{-1}$, respectively.

\footnotetext{
${ }^{1}$ College of Materials Science and Engineering, Sichuan University, Chengdu, China. ${ }^{2}$ CIRIMAT, Université de Toulouse, CNRS, Toulouse, France. ${ }^{3}$ Réseau sur le Stockage Electrochimique de l'Energie (RS2E), Le Mans, France. ${ }^{4}$ School of Machine Engineering, Dongguan University of Technology,

Dongguan, China. ${ }^{5}$ Engineering Laboratory of Advanced Energy Materials, Ningbo Institute of Materials Technology and Engineering, Chinese Academy of Sciences, Ningbo, Zhejiang, China. ${ }^{6}$ Qianwan Institute of CNiTECH, Ningbo, Zhejiang, China. ${ }^{7}$ These authors contributed equally: Guoliang Ma, Hui Shao.

凶email: liuying5536@scu.edu.cn; simon@chimie.ups-tlse.fr; linzifeng@scu.edu.cn
} 
M AX phases are ternary transition-metal carbides and nitrides with a formula of $\mathrm{M}_{n+1} \mathrm{AX}_{n}$, where $\mathrm{M}$ is a transition metal, $\mathrm{A}$ is an A-group element and $\mathrm{X}$ is carbon or nitrogen ${ }^{1}$. MXenes derived from MAX phase precursors have attracted great interest in many fields, including electrochemical energy storage ${ }^{2,3}$, electromagnetic interference (EMI) shielding ${ }^{4}$, superconductors ${ }^{5}$, and others ${ }^{6,7}$. Since the first report of $\mathrm{Ti}_{3} \mathrm{C}_{2} \mathrm{~T}_{x}$ synthesis in $2011^{8}$, MXenes have typically been prepared from selectively etching MAX phase precursors. However, these methods are difficult to upscale ${ }^{9}$ and/or take hours to days to obtain MXenes, which greatly reduces production efficiency and increases production costs. In addition, most synthesis methods are limited to the use of Al-containing MAX phase precursors, while many MAX phases with $\mathrm{Si}, \mathrm{Zn}, \mathrm{Ga}, \mathrm{Ge}$, and $\mathrm{S}$ elements are still difficult to etch. Recently, a molten salt synthesis method was reported where Lewis acidic melts were used to etch MAX phases with various A-site elements ( $\mathrm{Al}, \mathrm{Si}, \mathrm{Zn}$, and $\mathrm{Ga}$ ), which broadens the MAX precursors and enriches the family of MXenes ${ }^{10}$. Interestingly, this molten salt synthesis route allowed the preparation of surface $\mathrm{F}$-free, $\mathrm{Cl}$-containing MXene materials where a reversible, fast $\mathrm{Li}$-ion intercalation reaction was achieved when the MXene was tested as a working electrode active material in a nonaqueous half-cell configuration ${ }^{10}$. However, the time needed to fully etch the $\mathrm{Ti}_{3} \mathrm{SiC}_{2}$ MAX phase into $\mathrm{Ti}_{3} \mathrm{C}_{2} \mathrm{~T}_{x}$ MXene at $700{ }^{\circ} \mathrm{C}$ under inert gas protection was $24 \mathrm{~h}$.

In addition to the complexity of MXene synthesis, another obstacle for the large-scale application of MXenes comes from the high cost of MAX phase precursors since all MXene syntheses reported thus far use MAX phase powders as reactants. MAX phases are typically prepared at high temperature by hot-pressing, self-propagating high-temperature, spark plasma sintering, arc melting, and molten salt methods ${ }^{11}$. In 2019, Dash et al. proposed a molten salt shielded synthesis method (termed $\mathrm{MS}^{3}$ ) to prepare high-purity MAX phases under an air atmosphere at temperatures beyond $1000^{\circ} \mathrm{C}^{12}$. In this method, molten salts are used as the reaction medium that further protects the ceramic powders from oxidation during the high-temperature process by avoiding direct contact with air. Interestingly, Roy et al. reported that the synthesis of $\mathrm{MS}^{3}$-MAX phases may share the same supporting molten salts ( $\mathrm{NaCl}$ and $\mathrm{KCl}$ mixture) with the Lewis acid molten salt synthesis of MXenes ${ }^{13}$, except that different reaction temperatures and Lewis acidic salts (such as $\mathrm{CuCl}_{2}, \mathrm{ZnCl}_{2}, \mathrm{FeCl}_{2}$, and $\mathrm{NiCl}_{2}$ ) are needed for MXene preparation. This work reports the combination of the $\mathrm{MS}^{3}$ strategy and Lewis acid etching method for sequentially preparing MAX phases and in situ etching MXenes in one pot from the corresponding elemental substances. The obtained MXenes exhibit electrochemical Li-ion storage capability and pseudocapacitive characteristics in a nonaqueous electrolyte, and a maximum lithiation capacity of approximately $280 \mathrm{mAh} \mathrm{g}^{-1}$ was achieved for the $\mathrm{Ti}_{2} \mathrm{CT}_{x}$ electrode.

\section{Results}

Fig. 1 shows a sketch of the one-pot synthesis process of $\mathrm{Ti}_{3} \mathrm{C}_{2} \mathrm{~T}_{x}$ MXene in an air atmosphere. In this process, stoichiometric amounts of titanium, alumina and graphite powders are mixed with chloride salts $(\mathrm{NaCl}$ and $\mathrm{KCl})$ and pressed on a steel die to prepare a pellet. The pellet sample is further placed in a crucible and covered with a chloride salt bed. The crucible is heated in a muffle furnace under an air atmosphere. When the temperature reaches approximately $660^{\circ} \mathrm{C}$, the $\mathrm{NaCl}$ and $\mathrm{KCl}$ mixture melts, and the molten salt acts as the reactive medium and protects the reactants from oxidation at high temperatures by avoiding direct contact with air. $\mathrm{Ti}_{3} \mathrm{AlC}_{2}$ MAX phase synthesis is achieved by etching at $1300^{\circ} \mathrm{C}$ for $1 \mathrm{~h}$. The successful synthesis of the $\mathrm{Ti}_{3} \mathrm{AlC}_{2}$ MAX phase at $1300^{\circ} \mathrm{C}$ in molten salt illustrated in
Supplementary Fig. 1 is confirmed via powder X-ray diffraction measurements (Supplementary Fig. 2). After cooling the crucible down to $700{ }^{\circ} \mathrm{C}, \mathrm{CuCl}_{2}$ is added to the melts for in situ etching of the $\mathrm{Ti}_{3} \mathrm{AlC}_{2}$ MAX phase into $\mathrm{Ti}_{3} \mathrm{C}_{2} \mathrm{~T}_{x}$ MXene. $\mathrm{Ti}_{3} \mathrm{AlC}_{2}$ MAX phase etching occurs via reduction of $\mathrm{Cu}^{2}+$ ions into the $\mathrm{Cu}$ and concomitant $\mathrm{Al}$ oxidation into the volatile $\mathrm{AlCl}_{3}$ phase (boiling point of $181^{\circ} \mathrm{C}$ ), as described in our previous study ${ }^{10}$. After cooling to room temperature, the samples are washed with deionized (DI) water and ammonium persulfate (APS, $\left.\left(\mathrm{NH}_{4}\right)_{2} \mathrm{~S}_{2} \mathrm{O}_{8}\right)$ solution to dissolve the solidified salts and remove the $\mathrm{Cu}$ from the MXene particle surface ${ }^{10}$. The final product is collected by vacuum filtration and dried in an oven at $80^{\circ} \mathrm{C}$ for $12 \mathrm{~h}$. $\mathrm{Ti}_{2} \mathrm{CT}_{x}$ MXene is synthesized in a similar process, with the experimental details described in the Methods section.

Compared to the synthesis of the $\mathrm{MS}^{3}-\mathrm{Ti}_{3} \mathrm{AlC}_{2}$ MAX phase (as seen in Supplementary Fig. 1), the one-pot synthesis of $\mathrm{Ti}_{3} \mathrm{C}_{2} \mathrm{~T}_{x}$ MXene from elementary substances requires only a few more minutes for the additional in situ etching reaction step at $700{ }^{\circ} \mathrm{C}$ during the cooling process. The temperature is held for only 10 mins at $700{ }^{\circ} \mathrm{C}$ for the etching reaction, which is a very short time compared to other etching methods, where the reaction times range from several hours to days ${ }^{8,14-19}$. This might be associated with the small particle size of the in situ prepared $\mathrm{Ti}_{3} \mathrm{AlC}_{2}$ MAX phase. Finally, as a whole, the synthesis of $\mathrm{Ti}_{3} \mathrm{C}_{2} \mathrm{~T}_{x}$ MXene from raw $\mathrm{Ti}, \mathrm{Al}$, and $\mathrm{C}$ precursors, as starting materials, requires less than $8 \mathrm{~h}$ (Supplementary Table 1), which is faster and more efficient than conventional synthesis methods that need to prepare MAX phases and MXenes separately.

X-ray diffraction patterns and Rietveld refinement of the $\mathrm{MS}^{3}$ $\mathrm{Ti}_{3} \mathrm{AlC}_{2}$ MAX phase are shown in Supplementary Fig. 2 and Supplementary Fig. 3. The $\mathrm{MS}^{3}-\mathrm{Ti}_{3} \mathrm{AlC}_{2}$ MAX phase (space group of $\mathrm{P}_{3} / \mathrm{mmc}$ ) shows lattice parameters of $a=0.308 \mathrm{~nm}$ and $c=1.856 \mathrm{~nm}$, and only a few traces of $\mathrm{TiC}$ are detected. Figure $2 \mathrm{a}$ and Supplementary Fig. 4 show the one-dimensional (1D) and two-dimensional (2D) synchrotron X-ray diffraction (SXRD) patterns of $\mathrm{Ti}_{3} \mathrm{C}_{2} \mathrm{~T}_{x}$ MXene (10 mins of etching) after washing with APS solution. The diffraction rings in the $2 \mathrm{D}$ XRD pattern correspond to the diffraction peaks in the $1 \mathrm{D}$ XRD pattern, and the radius corresponds to the $2 \theta$ angle. The red arrows point to the diffraction peaks of the sample holder that can be observed with the blank test pattern (Supplementary Fig. 4a). The 1D diffraction pattern of $\mathrm{Ti}_{3} \mathrm{C}_{2} \mathrm{~T}_{x}$ MXene (Fig. 2a) is derived from the $2 \mathrm{D}$ pattern and analysed by GSAS-II software for Rietveld refinement. The experimental diffraction peaks match well with the calculated peaks, confirming the presence of $\mathrm{Ti}_{3} \mathrm{C}_{2} \mathrm{~T}_{x}$ MXene ${ }^{5}$. The Rietveld refinement result gives a space group of $\mathrm{P}_{3} / \mathrm{mmc}$ and lattice parameters of $a=0.318 \mathrm{~nm}$ and $c=2.213 \mathrm{~nm}$ (interlayer spacing $d=1.107 \mathrm{~nm}$ ), and traces of $\mathrm{Al}_{2} \mathrm{O}_{3}$ are detected. XRD patterns of $\mathrm{Ti}_{3} \mathrm{C}_{2} \mathrm{~T}_{x}$ MXenes prepared by etching at $700{ }^{\circ} \mathrm{C}$ for between 0 and 90 mins are shown in Supplementary Fig. 5a. Even without holding at $700{ }^{\circ} \mathrm{C}$ (denoted $0 \mathrm{~min}$ ), the $(00 l)$ peaks of the $\mathrm{Ti}_{3} \mathrm{AlC}_{2}$ MAX phase are missing, while intense $(00 l)$ peaks of $\mathrm{Ti}_{3} \mathrm{C}_{2} \mathrm{~T}_{x}$ MXene are observed, which suggests a complete and fast-etching process. Increasing the etching time does not lead to major changes in the XRD patterns since the diffraction patterns almost overlap over the full two-theta ranges when increasing the etching time at $700{ }^{\circ} \mathrm{C}$ (Supplementary Fig. 5a). In this work, a $\mathrm{Ti}_{3} \mathrm{C}_{2} \mathrm{~T}_{x}$ MXene sample prepared with $10 \mathrm{mins}$ of etching at $700{ }^{\circ} \mathrm{C}$ is then selected for further investigation. SEM images of $\mathrm{Ti}_{3} \mathrm{C}_{2} \mathrm{~T}_{x}$ MXene samples at low magnification (Fig. 2b) show many multilayered particles with an average size of less than $5 \mu \mathrm{m}$, indicating successful preparation of layered MXenes. The open structure is more clearly shown in Fig. 2c and Supplementary Fig. $5 \mathrm{c}-\mathrm{g}$, which is consistent with the previously reported result of $\mathrm{Ti}_{3} \mathrm{C}_{2} \mathrm{~T}_{x}$ MXene obtained by $\mathrm{HF}$ etching or other methods ${ }^{8}$. XRD and SEM characterizations of the 


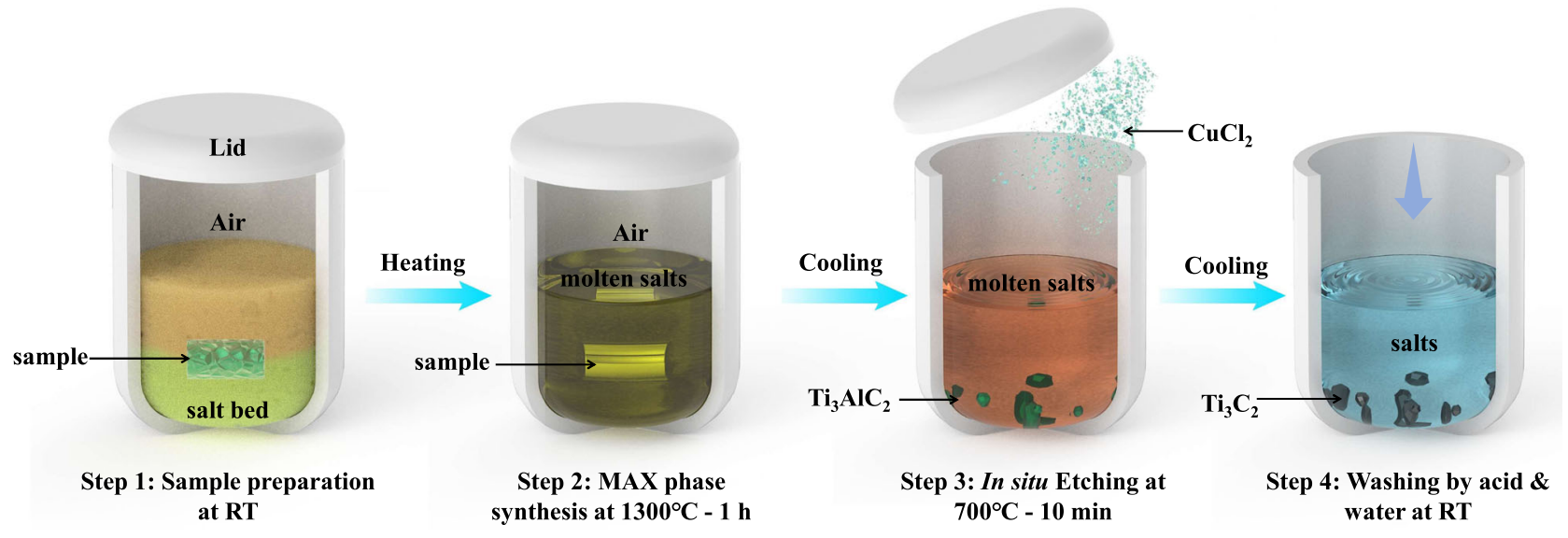

Fig. 1 One-pot synthesis of two-dimensional titanium-carbide in an air atmosphere. Schematic diagram of the one-pot synthesis of $T_{3} C_{2} T_{x} M X e n e$ in the open air with elemental $\mathrm{Ti}, \mathrm{Al}$, and $\mathrm{C}$ powders as starting materials. RT stands for room temperature. The sample pellet contains Ti:Al:C:NaCl:KCl powder with a mole ratio of 3:1.2:1.9:3:3; the salt bed is made of a $\mathrm{NaCl}$ and $\mathrm{KCl}$ mixture with a mole ratio of 1:1. The synthesis time for the whole process is 460 mins.
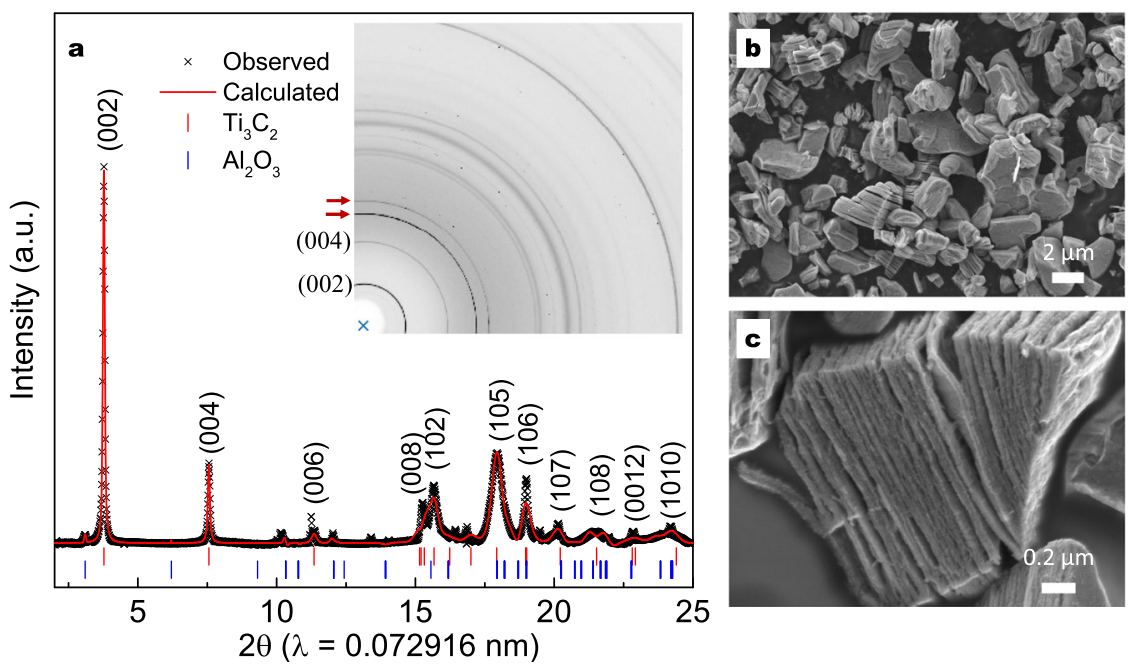

Fig. 2 Structural characterizations of $\mathbf{T i}_{\mathbf{3}} \mathbf{C}_{\mathbf{2}} \mathbf{T}_{\mathbf{x}}$. a $1 \mathrm{D}$ and $2 \mathrm{D}$ synchrotron $X$-ray $(\lambda=0.072916 \mathrm{~nm})$ diffraction (SXRD) patterns and Rietveld refinement of $\mathrm{Ti}_{3} \mathrm{C}_{2} \mathrm{~T}_{x}$ prepared by etching at $700^{\circ} \mathrm{C}$ for $10 \mathrm{~min}$. The red arrows in the $2 \mathrm{D}$ pattern point to the diffraction peaks of the sample holder; $\mathbf{b}, \mathbf{c}$ SEM images of $\mathrm{Ti}_{3} \mathrm{C}_{2} \mathrm{~T}_{x}$ with scale bars of $\mathbf{b} 2 \mu \mathrm{m}$ and $\mathbf{c} 0.2 \mu \mathrm{m}$.

$\mathrm{MS}^{3}-\mathrm{Ti}_{2} \mathrm{AlC}$ MAX phase and one-pot-synthesized $\mathrm{Ti}_{2} \mathrm{CT}_{x}$ MXene are presented in Supplementary Fig. 6. Diffraction peaks of $\mathrm{MS}^{3}-$ $\mathrm{Ti}_{2} \mathrm{AlC}$ are not observed in the diffraction pattern of $\mathrm{Ti}_{2} \mathrm{CT}_{x}$ MXene, leaving only characteristic peaks of $\mathrm{Ti}_{2} \mathrm{CT}_{x}$ MXene with low intensity (Supplementary Fig. 6a). Multilayered particles are also observed in the SEM images (Supplementary Fig. 6b, c), showing a similar open structure of $\mathrm{Ti}_{3} \mathrm{C}_{2} \mathrm{~T}_{x}$ MXene.

High-resolution TEM images (Fig. 3a and Supplementary Fig. 7) show the presence of $\mathrm{Ti}_{3} \mathrm{C}_{2} \mathrm{~T}_{x}$ MXene ribbons tens of nanometres wide and a few micrometres long. Each ribbon contains many $\mathrm{Ti}_{3} \mathrm{C}_{2} \mathrm{~T}_{x}$ layers, as presented in the TEM image along the $[11 \overline{2} 0]$ projection (Fig. 3b). Atomically resolved HAADF-STEM in combination with lattice resolved EDS is further used to obtain information about the local structure and composition of $\mathrm{Ti}_{3} \mathrm{C}_{2} \mathrm{~T}_{x}$ MXene. Fig. $3 c$, d show the atomic projections, with the electron beam oriented along the $[11 \overline{2} 0]$ and [1100] directions. Ordered $\mathrm{Ti}_{3} \mathrm{C}_{2} \mathrm{~T}_{x}$ MXene layers can be seen along the basal planes, which explains the intense $(00 l)$ peaks in the XRD patterns. Five atomic layers are clearly observed in the insets in Fig. $3 c$, d for each $\mathrm{Ti}_{3} \mathrm{C}_{2} \mathrm{~T}_{x}$ MXene layer. Combining the
EDS mapping results (Fig. 3e and Supplementary Fig. 8), the centred brighter atoms marked by red arrows indicate Ti atoms, while the green arrows indicate $\mathrm{Cl}$ atoms present on the surface of $\mathrm{Ti}_{3} \mathrm{C}_{2} \mathrm{~T}_{x}$ MXene layers. $\mathrm{Cl}$ atoms are located on the top of the centre layer of $\mathrm{Ti}$ atoms. This finding agrees well with the results of density functional theory (DFT) calculations, where the minimum energy state $(-0.958 \mathrm{eV})$ of $\mathrm{Cl}$ atoms is found on the top of the centre layer of $\mathrm{Ti}$ atoms but $\mathrm{O}$ atoms tend to be more stable at both the top of Ti and carbon atoms with an even lower energy state ${ }^{20,21}$, indicating that $\mathrm{O}$ is the dominant surface groups instead of $\mathrm{Cl}$ if oxygen is present in the etching environment. However, the good ordering of $\mathrm{Cl}$ atoms on $\mathrm{Ti}_{3} \mathrm{C}_{2} \mathrm{~T}_{x}$ layers suggests a Cl-rich surface and confirms that the $\mathrm{MS}^{3}$ method effectively protects MXene from oxidation. The carbon atoms are not visible in the STEM images but can be detected by EDS mapping. The carbon atoms are found to overlap with Ti atoms. The Al atoms are not observed between $\mathrm{Ti}_{3} \mathrm{C}_{2} \mathrm{~T}_{x}$ layers, suggesting the successful removal of $\mathrm{Al}$ by the etching reaction. The interlayer distance calculated from the high-resolution STEM images (Supplementary Fig. 9) is $1.169 \mathrm{~nm}$ along [11 $\overline{2} 0]$ and $1.203 \mathrm{~nm}$ 

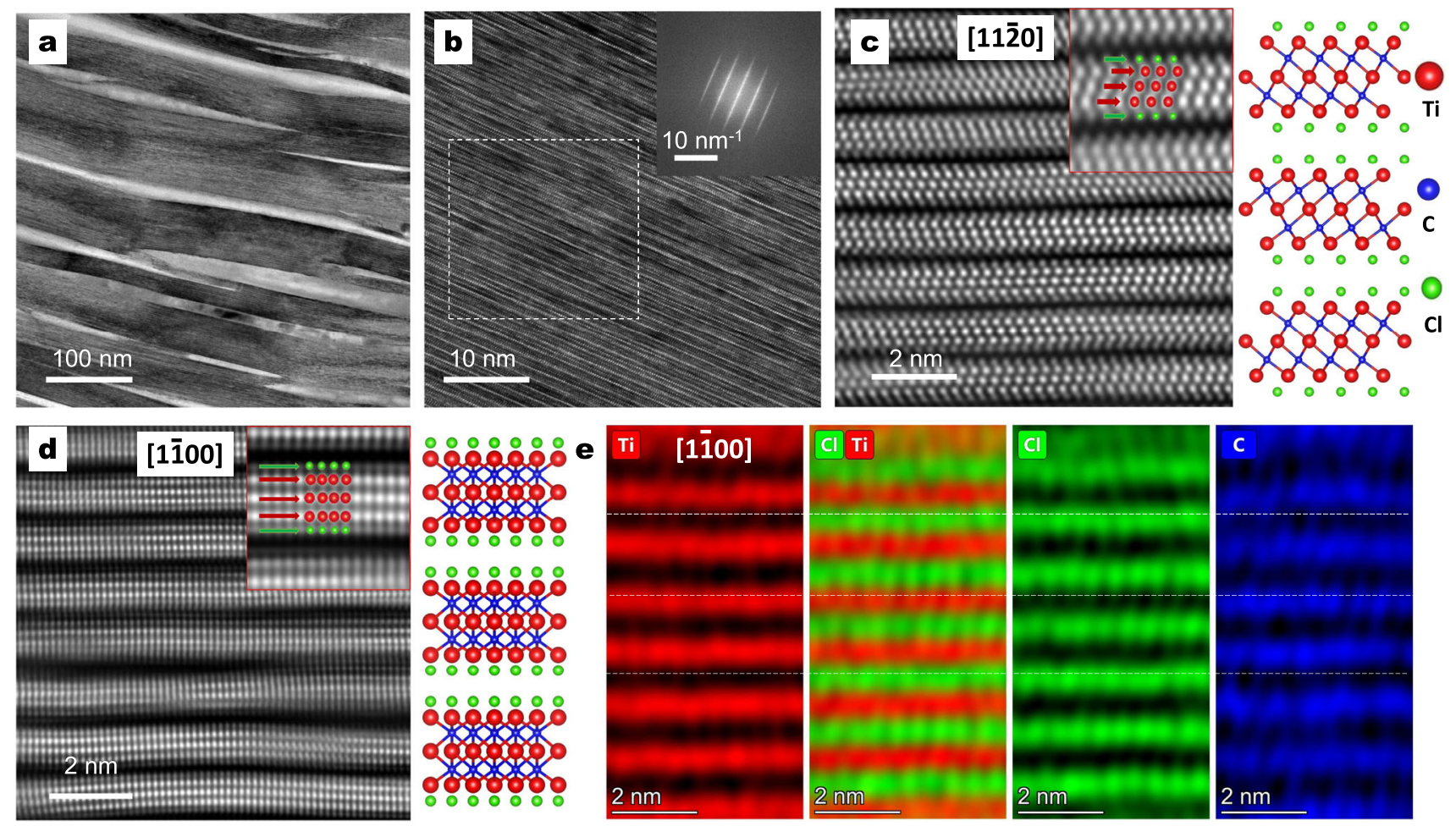

Fig. 3 Atomic structural analysis of $\mathrm{Ti}_{3} \mathbf{C}_{\mathbf{2}} \mathbf{T}_{\mathbf{x}} \mathbf{M X e n e}$ prepared by $\mathbf{1 0}$ mins of etching at $\mathbf{7 0 0}{ }^{\circ} \mathbf{C}$. High-resolution transmission electron microscopy images at a scale of $\mathbf{a} 100 \mathrm{~nm}$ and $\mathbf{b} 10 \mathrm{~nm}$, where the inset shows the fast Fourier transform (FFT) pattern of the selected region, with a scale bar of $1 / 10 \mathrm{~nm}$. Atomic-resolution high-angle annular dark-field (HAADF) images along with the c [1120] and d [1100] projections and the corresponding crystal structures; insets are enlarged views of the atomic positions. e Atomic-scale EDS mapping along the [1100] projection.

along [1100], which matches well with previously reported results ${ }^{5}$ and the SXRD measurement of $1.107 \mathrm{~nm}$. All these features demonstrate the successful preparation of $\mathrm{Ti}_{3} \mathrm{C}_{2} \mathrm{~T}_{x}$ MXene directly from elemental substances by the one-pot synthesis route.

The electrochemical properties of MXenes for $\mathrm{Li}^{+}$storage are investigated in a $1 \mathrm{M} \mathrm{LiPF}_{6}$ /ethylene carbonate-dimethyl carbonate electrolyte (see Methods for details). For both $\mathrm{Ti}_{3} \mathrm{C}_{2} \mathrm{~T}_{x}$ and $\mathrm{Ti}_{2} \mathrm{CT}_{x}$ electrodes, solid electrolyte interphase (SEI) formation was observed during the first cyclic voltammetry cycle and quickly stabilized after a few cycles (Supplementary Fig. 10). Fig. 4a presents the cyclic voltammetry (CV) profiles of the $\mathrm{Ti}_{3} \mathrm{C}_{2} \mathrm{~T}_{x}$ and $\mathrm{Ti}_{2} \mathrm{CT}_{x}$ electrodes recorded at a scan rate of $0.5 \mathrm{mV} \mathrm{s}^{-1}$ within the potential range from 0.1 to $3 \mathrm{~V}$ vs. $\mathrm{Li}^{+} / \mathrm{Li}$. The rectangular and highly symmetric $\mathrm{CV}$ profiles at a potential range from 0.1 to $2 \mathrm{~V}$ without the presence of visible redox peaks suggest a pseudocapacitive $\mathrm{Li}^{+}$storage mechanism, agreeing well with previously reported molten saltderived MXenes ${ }^{10}$. The pseudocapacitive behaviour is further evidenced by the CV profiles recorded with various negative cut-off potentials (Supplementary Fig. 11), where a continuously increasing cathodic current associated with $\mathrm{Li}^{+}$intercalation is observed for both MXene electrodes with decreased cut-off potentials. Fig. 4b shows the specific lithiation capacities versus time and scan rates calculated from the CV profiles in Supplementary Fig. 12, where the $\mathrm{Ti}_{2} \mathrm{CT}_{x}$ electrode is found to have a higher specific capacity than the $\mathrm{Ti}_{3} \mathrm{C}_{2} \mathrm{~T}_{x}$ electrode (Supplementary Tables 2 and 3). Specifically, the $\mathrm{Ti}_{2} \mathrm{CT}_{x}$ electrode delivers a specific capacity of up to $256 \mathrm{mAh}$ $\mathrm{g}^{-1}$ at a scan rate of $0.5 \mathrm{mV} \mathrm{s}^{-1}$, which corresponds to $318 \mathrm{Fg}^{-1}$ at a voltage of $2.9 \mathrm{~V}$. The $\mathrm{Ti}_{3} \mathrm{C}_{2} \mathrm{~T}_{x}$ electrode achieves a lower capacity of $164 \mathrm{mAh} \mathrm{g}^{-1}\left(204 \mathrm{~F} \mathrm{~g}^{-1}\right)$ at the same scan rate. Both MXene electrodes show superior rate performance and less $\mathrm{CV}$ distortion at increased scan rates (Supplementary Fig. 12). The $\mathrm{Ti}_{2} \mathrm{CT}_{x}$ electrode gives a specific capacity of $164 \mathrm{mAh} \mathrm{g}^{-1}$ at a scan rate of $10 \mathrm{mV} \mathrm{s}^{-1}$ and $76 \mathrm{mAh} \mathrm{g}^{-1}$ at a scan rate of $100 \mathrm{mV} \mathrm{s}^{-1}$, highlighting the high- rate capability of the $\mathrm{Ti}_{2} \mathrm{CT}_{x}$ electrode. Fig. $4 \mathrm{c}$ presents the voltage profiles of the $\mathrm{Ti}_{2} \mathrm{CT}_{x}$ electrode from galvanostatic tests. A maximum capacity of $277 \mathrm{mAh} \mathrm{g}^{-1}\left(344 \mathrm{~F} \mathrm{~g}^{-1}\right)$ is recorded at a low specific current of $0.1 \mathrm{~A} \mathrm{~g}^{-1}$. As the specific current increases, capacities of $162 \mathrm{mAh} \mathrm{g}^{-1}$ and $80 \mathrm{mAh} \mathrm{g}^{-1}$ are achieved by the $\mathrm{Ti}_{2} \mathrm{CT}_{x}$ electrode at specific currents of $2.0 \mathrm{~A} \mathrm{~g}^{-1}$ and $10 \mathrm{~A} \mathrm{~g}^{-1}$. The voltage profiles of the $\mathrm{Ti}_{3} \mathrm{C}_{2} \mathrm{~T}_{x}$ electrode from galvanostatic tests and a comparison of the specific capacities of the $\mathrm{Ti}_{3} \mathrm{C}_{2} \mathrm{~T}_{x}$ and $\mathrm{Ti}_{2} \mathrm{CT}_{x}$ electrodes in Supplementary Fig. 13 confirm the higher specific capacities of the $\mathrm{Ti}_{2} \mathrm{CT}_{x}$ electrode. The results obtained from galvanostatic tests are in good agreement with the CV measurements, highlighting the highrate electrochemical performance of the prepared MXenes. Electrochemical impedance spectroscopy measurements are performed at various potentials versus $\mathrm{Li}^{+} / \mathrm{Li}$ for the $\mathrm{Ti}_{2} \mathrm{CT}_{x}$ electrode, and the results are presented in Fig. 4d. All Nyquist plots start at a low resistance at high frequencies, and the charge transfer loops at mid frequencies are comparable. A rapid increase in the imaginary part of the impedance at low frequencies is observed for all Nyquist plots, indicating the pseudocapacitive behaviour of the $\mathrm{Ti}_{2} \mathrm{CT}_{x}$ electrode at the full potential range. The charge storage kinetics of the $\mathrm{Ti}_{3} \mathrm{C}_{2} \mathrm{~T}_{x}$ and $\mathrm{Ti}_{2} \mathrm{CT}_{x}$ electrodes are further estimated by using the $b$ value obtained from the following equation ${ }^{22}$ :

$$
i=a * v^{b}
$$

where $v$ is the scan rate and $i$ is the response current at a certain potential. It has been suggested that a $b$ value of 1 indicates a nondiffusion-controlled process (capacitive or capacitive-like behaviour), and a $b$ value of 0.5 relates to a diffusion-controlled process (battery behaviour). Various scan rates $\left(0.5-100 \mathrm{mV} \mathrm{s}^{-1}\right)$ and response specific currents (at $1 \mathrm{~V}$ vs. $\mathrm{Li}^{+} / \mathrm{Li}$ in the cathodic process) on a log scale are presented in Supplementary Fig. 14. A $b$ value of 0.87 is obtained for the $\mathrm{Ti}_{3} \mathrm{C}_{2} \mathrm{~T}_{x}$ electrode, which is slightly larger than the $0.85 b$ value of the $\mathrm{Ti}_{2} \mathrm{CT}_{x}$ electrode. A linear relationship is 

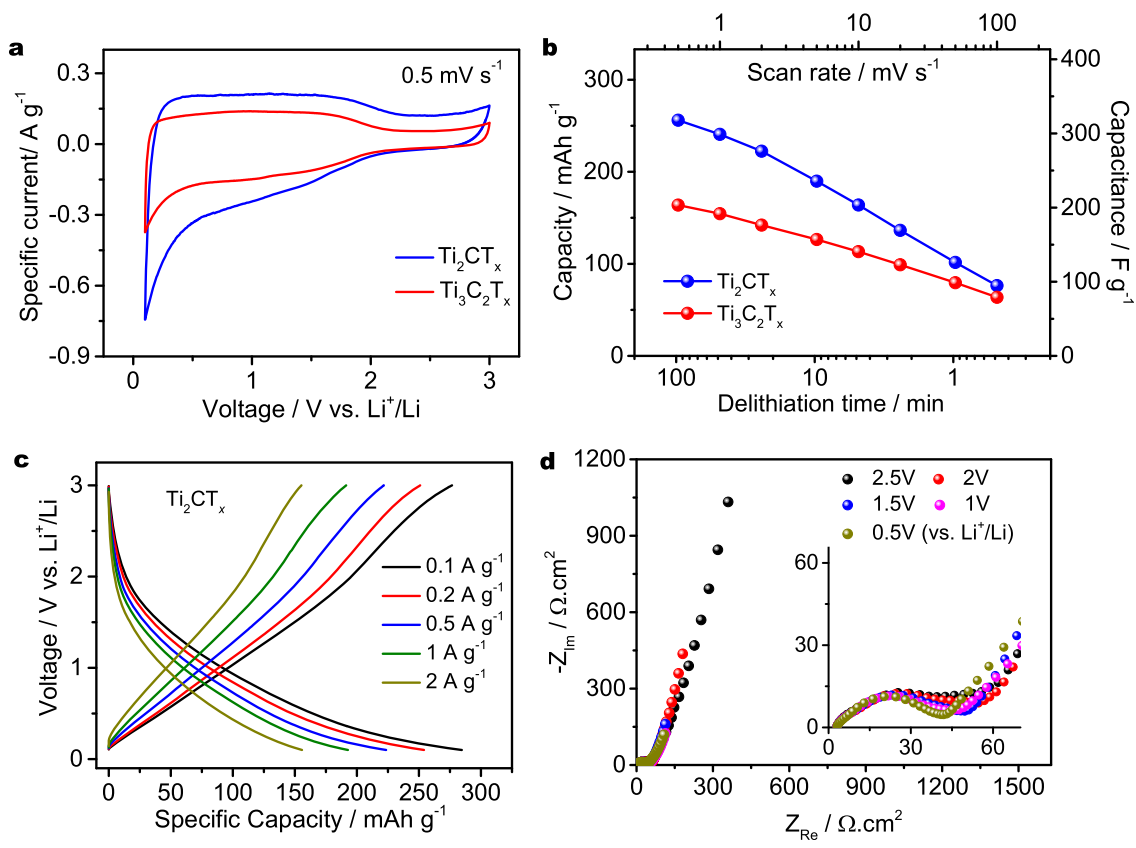

Fig. 4 Electrochemical energy storage properties of $\mathbf{T i}_{3} \mathbf{C}_{\mathbf{2}} \mathbf{T}_{\mathbf{x}}$ - and $\mathbf{T}_{\mathbf{2}} \mathbf{C} \mathbf{T}_{\mathbf{x}}$-based electrodes. a Cyclic voltammetry profiles of $\mathrm{Ti}_{3} \mathrm{C}_{2} T_{x}$ and $\mathrm{T}_{2} C \mathrm{CT}_{x} M \mathrm{Mene}$ at $0.5 \mathrm{mV} \mathrm{s} ;{ }^{-1} \mathbf{b}$ specific capacity comparison of $\mathrm{Ti}_{3} \mathrm{C}_{2} \mathrm{~T}_{x}$ and $\mathrm{T}_{2} \mathrm{CT}_{x} \mathrm{MXenes}$ at various scan rates; $\mathbf{c}$ voltage profiles of the $\mathrm{Ti}_{2} \mathrm{CT}_{x} \mathrm{MXene}$ electrode at various specific currents; $\mathbf{d}$ and electrochemical impedance measurements of the $\mathrm{Ti}_{2} \mathrm{CT}_{x}$ MXene electrode at various potentials.

observed in the low-scan rate range (less than $20 \mathrm{mV} \mathrm{s}^{-1}$ ) for both electrodes, suggesting that the charge storage at the corresponding time scale is not limited by $\mathrm{Li}^{+}$diffusion. The specific currents at higher scan rates of $50 \mathrm{mV} \mathrm{s}^{-1}$ and $100 \mathrm{mV} \mathrm{s}^{-1}$ deviate from the linear relationship, which could be explained by diffusion limitation and/or ohmic limitations at high specific currents.

In conclusion, we propose a facile one-pot synthesis method for preparing MXenes from elemental precursors in an air atmosphere. By eliminating the need for inert gas protection, the synthesis operation is greatly simplified, and the one-pot method reduces the whole synthesis duration compared to conventional MXene synthesis methods that prepare MAX phase precursors and MXenes separately. Cl-terminated $\mathrm{Ti}_{3} \mathrm{C}_{2} \mathrm{~T}_{x}$ and $\mathrm{T}_{2} \mathrm{CT}_{x}$ MXenes are prepared with a fast-etching step at $700{ }^{\circ} \mathrm{C}$ for only 10 mins and a whole synthesis duration of less than $8 \mathrm{~h}$. Lithiumion storage investigation suggests similar electrochemical signatures for the one-pot-synthesized MXenes and previously reported MXenes achieved by Lewis molten acid etching. The obtained $\mathrm{Ti}_{2} \mathrm{CT}_{x}$ MXene delivers lithiation capacity values of approximately $280 \mathrm{mAh} \mathrm{g}^{-1}$ and $160 \mathrm{mAh} \mathrm{g}^{-1}$ at specific currents of $0.1 \mathrm{~A} \mathrm{~g}^{-1}$ and $2 \mathrm{Ag}^{-1}$, respectively. We believe that the one-pot synthesis method paves the way for the facile and fast synthesis of MXene materials with lower production costs and sheds light on the promising potential of MXene materials for energy storage applications.

\section{Methods}

Materials. Ti powder (99\% pure, 325 mesh) was purchased from Alfa Aesar, Al $(99 \%$ pure, $500 \mathrm{~nm})$ was purchased from Yao Tian Nano Materials Co. Ltd., and Nano-graphite ( $99.5 \%$ pure, $100 \mathrm{~nm}$ ), $\mathrm{NaCl}\left(99.5 \%\right.$ pure), $\mathrm{KCl}$ ( $99.5 \%$ pure), $\mathrm{CuCl}_{2}$ (98\% pure), $\left(\mathrm{NH}_{4}\right)_{2} \mathrm{~S}_{2} \mathrm{O}_{8}$ (98\% pure) were purchased from Chron Chemicals.

MAX phase synthesized via $\mathbf{M S}^{\mathbf{3}}$ method. For preparing $\mathrm{Ti}_{3} \mathrm{AlC}_{2} \mathrm{MAX}$ phase, $\mathrm{Ti}$ $(1.45 \mathrm{~g}), \mathrm{Al}(0.33 \mathrm{~g})$ and $\mathrm{C}(0.23 \mathrm{~g})$ (3:1.2:1.9 by molar ratio) powders were mixed with $\mathrm{NaCl}(1.77 \mathrm{~g})$ and $\mathrm{KCl}(2.25 \mathrm{~g})$ salts. The mixture was pressed into a pellet with a diameter of $20 \mathrm{~mm}$ and a thickness of $9 \mathrm{~mm}$ by an axial force of $2 \mathrm{KN}$. The sample pellet was then placed in a corundum crucible, covered with the extra chloride salts of $\mathrm{NaCl}(7 \mathrm{~g})$ and $\mathrm{KCl}(9 \mathrm{~g})$. Then the crucible was placed in a muffle furnace without inert gas protection and heated $\left(10^{\circ} \mathrm{C} / \mathrm{min}\right.$ from room temperature to $1000^{\circ} \mathrm{C}, 5^{\circ} \mathrm{C} / \mathrm{min}$ from 1000 to $1300^{\circ} \mathrm{C}$ ) to the temperature of $1300^{\circ} \mathrm{C}$ and hold at this maximum temperature for $1-4 \mathrm{~h}$ for MAX phase synthesis reaction. $\mathrm{Ti}_{2} \mathrm{AlC}$ MAX phase was synthesized in a similar route by changing the amount of starting raw materials with Ti of $1.368 \mathrm{~g}, \mathrm{Al}$ of $0.462 \mathrm{~g}$ and $\mathrm{C}$ of $0.171 \mathrm{~g}$ and reaction temperature of $1000^{\circ} \mathrm{C}$.

MXenes synthesized via one-pot method. For preparing $\mathrm{Ti}_{3} \mathrm{C}_{2} \mathrm{~T}_{x}$ MXene, $\mathrm{Ti}$ $(1.45 \mathrm{~g}), \mathrm{Al}(0.33 \mathrm{~g})$, and $\mathrm{C}(0.23 \mathrm{~g})$ (3:1.2:1.9 molar ratio) elemental powders were weighed and mixed with $\mathrm{NaCl}(1.77 \mathrm{~g})$ and $\mathrm{KCl}(2.25 \mathrm{~g})$ salts. The mixture was pressed into a pellet with a diameter of $20 \mathrm{~mm}$ and a thickness of $9 \mathrm{~mm}$ by an axial force of $2 \mathrm{KN}$. The sample pellet was then placed in a corundum crucible, covered with the inorganic salt mixture of $\mathrm{NaCl}$ and $\mathrm{KCl}(\mathrm{NaCl}: \mathrm{KCl}=1: 1,16 \mathrm{~g})$. Then the crucible was placed in a muffle furnace without inert gas protection and heated to $1300^{\circ} \mathrm{C}\left(10^{\circ} \mathrm{C} / \mathrm{min}\right.$ to $1000^{\circ} \mathrm{C}, 5^{\circ} \mathrm{C} / \mathrm{min}$ from $1000^{\circ} \mathrm{C}$ to $\left.1300^{\circ} \mathrm{C}\right)$ and held for $1 \mathrm{~h}$. Then the temperature was cooled down to $700^{\circ} \mathrm{C}$ where $(8.3 \mathrm{~g}) \mathrm{CuCl}_{2}$ etching agent was added. After holding at $700^{\circ} \mathrm{C}$ for a duration ranges from 0 to $90 \mathrm{~min}$, the furnace was then cooled to room temperature. The resulting MXene product was washed with deionization water to remove the inorganic salt and then washed with $0.2 \mathrm{~mol}\left(\mathrm{NH}_{4}\right)_{2} \mathrm{~S}_{2} \mathrm{O}_{8}$ to remove the $\mathrm{Cu}$ elemental substance. $\mathrm{Ti}_{2} \mathrm{CT}_{x}$ MXene was synthesized in the same procedure with differences in the molar ratio of starting raw materials $(1.368 \mathrm{~g} \mathrm{Ti}, 0.462 \mathrm{~g} \mathrm{Al}, 0.171 \mathrm{~g} \mathrm{C}$ by a molar ratio of 2:1.2:1), and the maximum reaction temperature is $1000^{\circ} \mathrm{C}$ instead of $1300^{\circ} \mathrm{C}$. The etching temperature and etching duration are the same.

Materials characterizations. The phase structure was analysed by X-ray diffraction (D8 Advance, Bruker AXS, Germany) with Cu Ka radiation. Synchrotron XRD was carried out at beamline BL17B of National Facility for Protein Science in Shanghai (NFPS) at Shanghai Synchrotron Radiation Facility. The wavelength of the X-ray is $0.072916 \mathrm{~nm}$. The two-dimensional diffraction patterns were calibrated using a standard lanthanum boride sample and converted to one-dimensional patterns using GSAS-II software. For the obtained SXRD data analysis, the GSAS-II software was used to fit the observed diffraction patterns and obtain the lattice parameters ${ }^{23}$.

The microstructure and chemical composition were analysed by scanning electron microscopy (SEM, JEOL, JSM-7900F) and spherical aberration-corrected transmission electron microscopy equipped with two aberration correctors (ACTEM, FEI Titan Themis 80-300). The local element distribution (maps and line scans) was analysed by highly efficient energy dispersive X-ray (EDX) spectroscopy at $300 \mathrm{kV}$ with a point-to-point resolution of $0.2 \mathrm{~nm}$ and a maximum resolution of $0.06 \mathrm{~nm}$ in a high-angle annular dark-field (HAADF) high-resolution scanning transmission electron microscopy (STEM). The samples for crosssectional transmission electron microscopy (TEM) were prepared by an FEI HELIOS NanoLab 600i Focused Ion Beam (FIB) system.

Electrochemical characterizations. To prepare working electrodes, MXene powders, acetylene carbon black, and polyvinylidene fluoride or polyvinylidene difluoride (PVDF) were mixed in a weight ratio of 78:15:7. Then a slurry was 
prepared by dispersing the mixture in N-Methyl-2-pyrrolidone (NMP) and coated onto a $\mathrm{Cu}$ foil by a typical doctor-blade method. After drying overnight at $80^{\circ} \mathrm{C}$ under vacuum, $12 \mathrm{~mm}$-diameter discs were cut and used as the working electrodes. The loading mass of MXene electrodes is $0.85( \pm 0.1) \mathrm{mg} \mathrm{cm}^{-2}$ based on active materials, and the thickness of MXenes electrodes is $8( \pm 1) \mu \mathrm{m}$ (measured by a digital micrometre, QuantuMike IP65).

CR2032 coin cells using MXene electrodes as working electrode and Li foil (purchased from Sigma-Aldric, purity of $99.9 \%$, thickness $=0.75 \mathrm{~mm}$, diameter $=13 \mathrm{~mm}$ ) as a counter electrode, one layer of glass microfiber A (purchased from Whatman) as the separator, and commercially available $1 \mathrm{M}$ $\mathrm{LiPF}_{6} /$ ethylene carbonate-dimethyl carbonate (1:1 vol.\%, purchased from Solvionic, purity of $99.9 \%$, water content less than $20 \mathrm{ppm}$ ) as an electrolyte, were assembled in an argon-filled glovebox, with $\mathrm{H}_{2} \mathrm{O}$ and $\mathrm{O}_{2}$ content less than $0.1 \mathrm{ppm}$.

Electrochemical tests were conducted by using a Biologic VMP3 potentiostat at room temperature $23( \pm 3)^{\circ} \mathrm{C}$. Electrochemical impedance spectroscopy (EIS) measurements were carried out in a two-electrode cell configuration. Specifically, each EIS plot at various biased voltage versus Li metal was recorded in a frequency range of $10 \mathrm{mHz}$ to $200 \mathrm{kHz}$ (10 points per decade) with a potential amplitude of $10 \mathrm{mV}$. Before each EIS measurement, linear sweep voltammetry with a scan rate of $0.5 \mathrm{mV} \mathrm{s}^{-1}$ was applied to reach the desired voltage and followed by a rest time of 10 mins at this voltage.

Specific capacitance and capacity values derived from the cyclic voltammetry profiles were calculated from anodic scan curves following:

$$
\begin{gathered}
C=\frac{\int_{0}^{t}|i| d t}{V m} \\
Q_{c}=C V \\
Q_{m}=\frac{Q_{c}}{3.6}
\end{gathered}
$$

where $C$ is the gravimetric capacitance $\left(\mathrm{F} \mathrm{g}^{-1}\right), V$ is the voltage window $(V)$, $\mathrm{t}$ is the recording time (s), $i$ is the response current $(A), m$ is the mass of the working electrode $(g), \mathrm{Q}_{\mathrm{c}}$ (in $C \mathrm{~g}^{-1}$ ) and $\mathrm{Q}_{\mathrm{m}}$ (in $\mathrm{mAh} \mathrm{g}^{-1}$ ) are the gravimetric capacities.

\section{Data availability}

The data that support the findings of this study are available from the corresponding authors upon reasonable request.

Received: 23 April 2021; Accepted: 9 July 2021;

Published online: 24 August 2021

\section{References}

1. Sokol, M., Natu, V., Kota, S. \& Barsoum, M. W. On the chemical diversity of the MAX phases. Trends Chem. 1, 210-223 (2019).

2. Anasori, B., Lukatskaya, M. R. \& Gogotsi, Y. 2D metal carbides and nitrides (MXenes) for energy storage. Nat. Rev. Mater. 2, 16098 (2017).

3. Lin, Z., Shao, H., Xu, K., Taberna, P.-L. \& Simon, P. MXenes as high-rate electrodes for energy storage. Trends Chem. 2, 654-664 (2020).

4. Shahzad, F. et al. Electromagnetic interference shielding with 2D transition metal carbides (MXenes). Science. 353, 1137-1140 (2016).

5. Kamysbayev, V. et al. Covalent surface modifications and superconductivity of two-dimensional metal carbide MXenes. Science 369, 979-983 (2020).

6. Liu, S. et al. Hydrogen storage in incompletely etched multilayer $\mathrm{Ti}_{2} \mathrm{CT}_{\mathrm{x}}$ at room temperature. Nat. Nanotechnol. 16, 331-336 (2021).

7. Bao, W. et al. Porous cryo-dried MXene for efficient capacitive deionization. Joule. 2, 778-787 (2018).

8. Naguib, M. et al. Two-dimensional nanocrystals produced by exfoliation of $\mathrm{Ti}_{3} \mathrm{AlC}_{2}$. Adv. Mater. 23, 4248-4253 (2011).

9. Verger, L., Natu, V., Carey, M. \& Barsoum, M. W. MXenes: an introduction of their synthesis, select properties, and applications. Trends Chem. 1, 656-669 (2019).

10. Li, Y. et al. A general Lewis acidic etching route for preparing MXenes with enhanced electrochemical performance in non-aqueous electrolyte. Nat. Mater. 19, 894-899 (2020).

11. Haemers, J., Gusmão, R. \& Sofer, Z. Synthesis protocols of the most common layered carbide and nitride MAX phases. Small Methods. 4, 1900780 (2020).

12. Dash, A., Vaßen, R., Guillon, O. \& Gonzalez-Julian, J. Molten salt shielded synthesis of oxidation prone materials in air. Nat. Mater. 18, 465-470 (2019).

13. Roy, C., Banerjee, P. \& Bhattacharyya, S. Molten salt shielded synthesis (MS ${ }^{3}$ ) of $\mathrm{Ti}_{2} \mathrm{AlN}$ and $\mathrm{V}_{2} \mathrm{AlC}$ MAX phase powders in open air. Journal of the European Ceramic Society. 40, 923-929 (2020).

14. Liu, F. et al. Preparation of $\mathrm{Ti}_{3} \mathrm{C}_{2}$ and $\mathrm{Ti}_{2} \mathrm{C}$ MXenes by fluoride salts etching and methane adsorptive properties. Appl. Surf. Sci. 416, 781-789 (2017).
15. Alhabeb, M. et al. Selective etching of silicon from $\mathrm{Ti}_{3} \mathrm{SiC}_{2}$ (MAX) to obtain 2D titanium carbide (MXene). Angew. Chem. 130, 5542-5546 (2018).

16. Natu, V. et al. 2D $\mathrm{Ti}_{3} \mathrm{C}_{2} \mathrm{~T}_{\mathrm{z}}$ MXene synthesized by water-free etching of $\mathrm{Ti}_{3} \mathrm{AlC}_{2}$ in polar organic solvents. Chem. 6, 616-630 (2020).

17. Husmann, S. et al. Ionic liquid-based synthesis of MXene. Chem. Commun. 56, 11082-11085 (2020).

18. Li, M. et al. Element replacement approach by reaction with Lewis acidic molten salts to synthesize nanolaminated MAX phases and MXenes. J. Am. Chem. Soc. 141, 4730-4737 (2019).

19. Lukatskaya, M. R. et al. Ultra-high-rate pseudocapacitive energy storage in two-dimensional transition metal carbides. Nat. Energy 2, 17105 (2017).

20. Dong, $\mathrm{H}$. et al. Molten salt derived $\mathrm{Nb}_{2} \mathrm{CT}_{\mathrm{x}}$ MXene anode for Li-ion batteries. ChemElectroChem. 8, 957-962 (2021).

21. Lu, J. et al. $\mathrm{Ti}_{n+1} \mathrm{C}_{\mathrm{n}}$ MXenes with fully saturated and thermally stable $\mathrm{Cl}$ terminations. Nanoscale Adv. 1, 3680-3685 (2019).

22. Wang, J., Polleux, J., Lim, J. \& Dunn, B. Pseudocapacitive contributions to electrochemical energy storage in $\mathrm{TiO}_{2}$ (Anatase) nanoparticles. J. Phys. Chem. C. 111, 14925-14931 (2007).

23. Toby, B. H. \& Von Dreele, R. B. GSAS-II: the genesis of a modern open-source all purpose crystallography software package. J. Appl. Crystallogr. 46, 544-549 (2013).

\section{Acknowledgements}

This study was supported by the National Natural Science Foundation of China (Grant No. 52072252, No. 51902215), and Sichuan Science and Technology Program (No. 2020ZDZX0005), and the Fundamental Research Funds for the Central Universities (YJ201886). P.S., P-L.T., and H.S. thank the Agence Nationale de la Recherche (Labex STORE-EX) for financial support. Q.H. was supported by Leading Innovative and Entrepreneur Team Introduction Program of Zhejiang (Grant No. 2019R01003), Ningbo Top-talent Team Program, Ningbo Municipal Bureau of Science and Technology (Grant No. 2018A610005), President's International Fellowship Initiative of CAS (No. 2021DE0002). We thank the staffs from BL17B1 beamline of National Facility for Protein Science in Shanghai (NFPS) at Shanghai Synchrotron Radiation Facility, for assistance during data collection.

\section{Author contributions}

Z.F.L. designed the research. G.L.M. conducted material preparations and characterizations. H.S. conducted the electrochemical test and analysed the data. J.X carried out the synchrotron XRD test. Z.F.L., P.S., Y.L, P.L.T., Q.H., and H.S. prepared the manuscript. All authors contributed to the discussion of the data.

\section{Competing interests}

The authors declare no competing interests.

\section{Additional information}

Supplementary information The online version contains supplementary material available at https://doi.org/10.1038/s41467-021-25306-y.

Correspondence and requests for materials should be addressed to Y.L., P.S. or Z.L.

Peer review information Nature Communications thanks Mark Bissett and the other anonymous reviewers for their contribution to the peer review of this work. Peer reviewer reports are available.

Reprints and permission information is available at http://www.nature.com/reprints

Publisher's note Springer Nature remains neutral with regard to jurisdictional claims in published maps and institutional affiliations.

Open Access This article is licensed under a Creative Commons Attribution 4.0 International License, which permits use, sharing, adaptation, distribution and reproduction in any medium or format, as long as you give appropriate credit to the original author(s) and the source, provide a link to the Creative Commons license, and indicate if changes were made. The images or other third party material in this article are included in the article's Creative Commons license, unless indicated otherwise in a credit line to the material. If material is not included in the article's Creative Commons license and your intended use is not permitted by statutory regulation or exceeds the permitted use, you will need to obtain permission directly from the copyright holder. To view a copy of this license, visit http://creativecommons.org/ licenses/by/4.0/.

(C) The Author(s) 2021 